\title{
Nutritional enrichment of rotifer Brachionus plicatilis and its effect on clownfish larvae Amphiprion clarkii (Bennett, 1830)
}

\author{
SWAGAT GHOSH ${ }^{1,2}$, T. T. AJITH KUMAR ${ }^{1,3}$, BANDANA DAS GHOSH ${ }^{1}$ AND \\ N. C. SAHU ${ }^{2}$ \\ ${ }^{1}$ Centre of Advanced Study in Marine Biology, Faculty of Marine Sciences, Annamalai University \\ Parangipettai - 608 502, Tamil Nadu, India \\ ${ }^{2}$ Sasya Shyamala Krishi Vigyan Kendra, Indian Council of Agricultural Research (ICAR), Ramakrishna Mission \\ Vivekananda University, Kolkata - 700 150, West Bengal, India \\ ${ }^{3}$ ICAR-National Bureau of Fish Genetic Resources, Dillkhusha, Lucknow - 226 002, Uttar Pradesh, India \\ e-mail: swagotor@gmail.com
}

\begin{abstract}
The present study, evaluated the effect of enrichment of the rotifer Brachionus plicatilis with the microalga Nannochloroposis salina, amino acid derivative L-carnitine and commercially available S-presso (SELCO). The study also evaluated the effect of enriched rotifers in larval rearing of Amphiprion clarkii in terms of metamorphosis, pigmentation, growth and survival of larvae: Rotifer production increased by 43,39 and $54 \%$ respectively in B. plicatilis enriched with different concentrations of L-carnitine at 1,10 and $100 \mathrm{mg} \mathrm{l}^{-1}$ on day $4(\mathrm{p}<0.001)$ in comparison with the control group maintained on algal diet alone. Total unsaturated fatty acid (PUFA, HUFA and n-3 fatty acids) and the ratios of n-3/ n-6, DHA/EPA, EPA/AA were significantly higher $(\mathrm{p}<0.05)$ in the L-carnitine treated rotifers compared with the S-presso enriched as well $N$. salina enriched groups. Larvae of $A$. clarkii, fed with L-carnitine enriched rotifer achieved maximum growth of $56.92 \pm 0.2 \mathrm{mg}$; whereas, those fed S-presso treated rotifers attained only $48.74 \pm 1 \mathrm{mg}$. In L-carnitine enrichment; metamorphosis of clown fish larvae took only 10 days, while it took 11 days and 10 days respectively in S-presso and $N$. salina enrichment. In L-carnitine and S-presso enrichments, initial pigmentation of larvae was observed within first 3-4 days of culture, whereas it took 4-5 days in $N$. salina enrichment. L-carnitine enrichment resulted in the highest survival of $70 \%$, followed by N. salina with $68 \%$ and S-presso enriched group with $52 \%$. The results indicate that L-carnitine could be a recommendable enrichment for increasing rotifer production as well as for clown fish larval culture.
\end{abstract}

Keywords: Amphiprion clarkii, Enrichment, Growth, L-carnitine, Rotifer, Survival

Rotifers are rich source of highly unsaturated fatty acids (HUFAs), 20:5n-3 and 22:6n-3, which are essential for survival of marine fish larvae (Segner et al., 1984). The essential fatty acids (EFAs) and additional nutritive elements present in microalgae could be transferred to fish larvae easily by bio-encapsulation of rotifers (Watanabe et al., 1983). In the present study, L-carnitine and the commercially available S-presso (SELCO) were used along with the microalga Nannochloroposis salina. L-carnitine has vital role in enhancing oxidation process of long chain fatty acids through mitochondrial stimulation with protein sparing stroke by cumulative dynamism derived from lipids (Emaus and Bieber, 1983). Despite conflicting outcomes, L-carnitine enriched feeding management were used as supplement for vitamin-like nutrient which improves fish growth, stress tolerance, excess fat reduction, stimulation of lipid metabolism and reproduction (Zhang et al., 2002).

Rotifers form prime initial larval microscopic live feed for early stages of fish larvae. The rotifer population and growth can be enhanced through environmental manipulations and chemical treatments (Dhert et al., 2001; Hagiwara et al., 2001). Dietary influences of essential elements like vitamins and fatty acids have been established through mass culture of rotifers (Yoshimatsu et al., 1997). L-carnitine enrichments have been shown to influence metabolic activities in rotifers which also helps to improve growth and reproductive pattern of rotifers by way of lipid catabolism and similarly it works on the early stages of fish larvae. Therefore, this study evaluated the effects of L-carnitine enrichments on reproduction, growth and population density of rotifers in comparison with S-presso and $N$. salina enrichments. The study also assessed the effect of enriched rotifers in larval rearing of the clownfish, Amphiprion clarkii with special emphasis on larval weight, specific growth rate, biomass and survival.

L-carnitine (Inertsalt, 98\%) (Sigma-Aldrich) and S-presso (SELCO, INVE) were used at concentrations 
of $0,0.001,0.01,0.1,1,10,100$ and $1000 \mathrm{mg}$ along with $N$. salina culture at $7 \times 10^{6}$ cells ml $^{-1}$ in glass test tubes. S-type rotifer, Brachionus plicatilis was used for the experiments. The egg bearing females were collected in a screw-capped bottle and the eggs were collected by shaking. Females among the neonatal rotifers with single egg were pipetted out one by one and collected in test tubes which already contained $5 \mathrm{ml}$ of different enrichments. The experiment was conducted with different enrichments in medium having

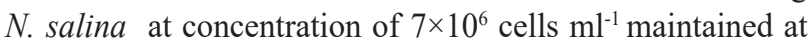
same temperature which was renewed at every $48 \mathrm{~h}$.

The experimental conditions were maintained with filtered seawater at temperature of $30 \pm 2^{\circ} \mathrm{C}$, salinity $26 \pm 2 \% 0$ and natural photoperiod. Initial concentration of rotifers was 25 Ind. $\mathrm{ml}^{-1}$ and it was examined daily in $1 \mathrm{ml}$ samples from all treatments.

The egg ratio was calculated using the formula (Zhang et al., 2002):

Egg ratio $=$ No. of amictic eggs $/$ No. of rotifers

The body size of rotifer, in terms of lorica length and width were measured using a microscope (Leica, ATC2000) with computed length analysis software on the last day of the culture trial. One-egg carrying rotifer was randomly measured $(n=120$, per treatment). For easy measurement, without significant shrinkage, rotifers were fixed with $6.5 \%$ $\mathrm{HCl}$ (Fu et al., 1991).

After enrichment, the rotifers were washed using filtered seawater and were collected in small vials and stored at $-80^{\circ} \mathrm{C}$ till further analysis. Total lipids were extracted from the enriched rotifers as per Bligh and Dyer method (1959) at A to Z Pharmaceuticals Laboratory, Chennai and the fatty acid analysis was done using Gas Chromatography (Chrompak CP- 9001, Gas Chromatograph).

Six larval rearing experimental units comprising 1001 capacity rectangular fibre re-inforced plastic (FRP) tanks with aeration were set up. Water quality parameters were analysed as described by Albentosa et al. (1997) and were maintained in the ranges of: temperature $30-34^{\circ} \mathrm{C}, \mathrm{pH} 8.0-8.2$, salinity $24-32 \%$ and ammonia $<0.01 \mathrm{ppm}$. Rotifer concentration in the rearing water was maintained at $8-10$ nos. $\mathrm{ml}^{-1}$ and 60 nos. of larvae each measuring $0.05-0.15 \mathrm{mg}$ were individually counted and introduced in each larval rearing tank. Every morning, tanks were monitored, dead larvae were counted and removed along with the debris settled in the bottom by siphoning. About $20 \%$ water exchange was done in all the experimental tanks from the third day onwards. Enriched rotifers were fed to the larvae during early morning hours. Experiment was continued for a period 15 days and the final wet weight of fish larvae was taken. During the experimental period, growth in terms of weight, survival and number of days taken for pigmentation and metamorphosis were recorded.

Larval dry weight was estimated by weighing on pre-washed and pre-weighed fibreglass filters (Zhang et al., 2002). Specific growth rate (SGR) was calculated from the slope of the linear regression of log-transformed dry weight against age (Albentosa et al., 1997). Final biomass was calculated from the dry weight and the larval density at the end of the experiment (Cahu et al., 1998).

Values on population density were transformed to a logarithmic scale for the purpose of statistical analysis. One-way ANOVA was conducted to identify significant differences among treatments on each day by Duncan's multiple range test (DMRT) (Zar, 1999). Differences were considered significant at 0.05 probability level. All statistical analyses were performed with SPSS 20.0 and graph made in Origin 6.1 software.

The population density in all the treatments of enriched rotifers were significantly different $(\mathrm{p}<0.05)$. Density of rotifers in $1000 \mathrm{mg} \mathrm{l}^{-1}$ L-carnitine enrichment was significantly lower $(\mathrm{p}<0.05)$ compared to control on $5^{\text {th }}$ day of culture and $100 \%$ mortality was observed by $10^{\text {th }}$ day of culture. Significantly $(\mathrm{p}<0.05)$ high population density was recorded in $10 \mathrm{mg} \mathrm{l}^{-1} \mathrm{~L}$-carnitine enrichment on the $5^{\text {th }}$ day. Population density in groups treated with 0 to $10 \mathrm{mg}$ $1^{-1} \mathrm{~L}$-carnitine exhibited a clear increasing tendency during the 10 days culture period (Fig. 1 and 2). In contrast, population density of rotifers in the 100 and $1000 \mathrm{mg} \mathrm{l}^{-1}$ treatments showed a decreasing trend. The specific growth rate in all treatments decreased during the last 5 days, compared to the initial 5 days.

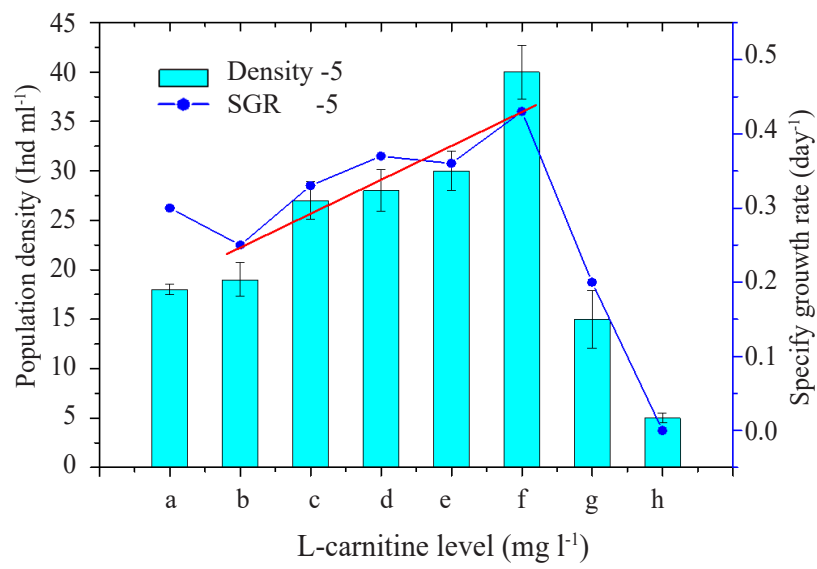

Fig. 1. Population density (ind. $\mathrm{ml}^{-1}$ ) and specific growth rate $\left(\right.$ day $\left.^{-1}\right)$ of $B$. plicatilis enriched with different levels of L-carnitine after 5 days of culture $(\mathrm{a}, \mathrm{b}, \mathrm{c}, \mathrm{d}$, e and f refer to concentrations of $0,0.001,0.01,0.1,1.0,10,100$ and $1000 \mathrm{mg} \mathrm{l}^{-1}$ of L-carnitine respectively). 


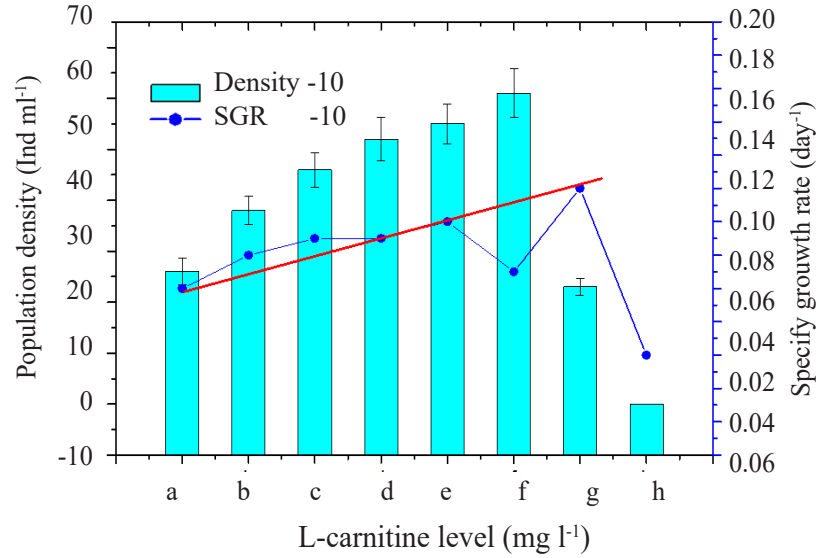

Fig. 2. Population density (ind. $\mathrm{ml}^{-1}$ ) and specific growth rate $\left(\right.$ day $\left.^{-1}\right)$ of $B$. plicatilis enriched with different levels of L-carnitine after 10 days of culture. (a, b, c, d, e, f, g and $\mathrm{h}$ refer to concentrations of $0,0.001,0.01,0.1$, $1.0,10,100$ and $1000 \mathrm{mg} \mathrm{l}^{-1}$ of L-carnitine respectively)

Significantly lower egg ratios were recorded in 1 to $10 \mathrm{mg}^{-1}$ treatments on day $4(\mathrm{p}<0.01)$ of culture compared to the higher levels. On day 5, the egg ratios in all groups decreased ( $p>0.05$ ) (Fig. 3).

Body size of the rotifers differed $(\mathrm{p}<0.05)$ significantly between different treatments. Length $(\mathrm{p}<0.001)$ and width $(\mathrm{p}<0.05)$ of the lorica were significantly lower in $1000 \mathrm{mg} \mathrm{l}^{-1}$ treatment. In 1, 10 and $100 \mathrm{mg} \mathrm{l}^{-1}$ L-carnitine treated rotifers, body size (Fig. 4) and length were significantly higher $(p<0.05)$. A significantly higher body width $(p<0.05)$ and length $(\mathrm{p}<0.001)$ were observed at $100 \mathrm{mg} \mathrm{l}^{-1}$ treatment. There were no significant difference in body size between $10 \mathrm{mg} \mathrm{l}^{-1}$ treatment and the control $\left(0 \mathrm{mg} \mathrm{l}^{-1}\right)(\mathrm{p}<0.05)$.

Rotifer samples were analysed in duplicate and both saturated and unsaturated fatty acid percentage were detected

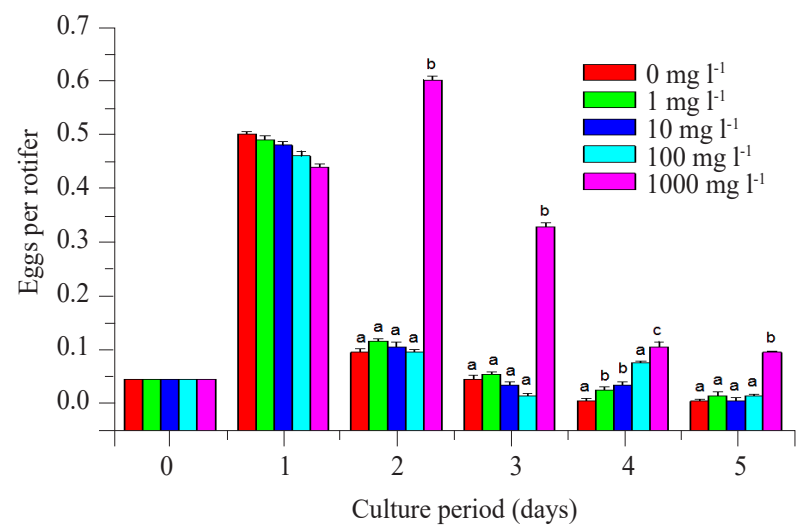

Fig. 3. Egg ratio of B. plicatilis during 5 day batch culture enriched with different levels of L-carnitine $(0,1,10,100$ and $1000 \mathrm{mg} \mathrm{l}^{-1}$ ) [Different alphabets on top of bars indicate significant difference between treatments $(p<0.05)$ ]

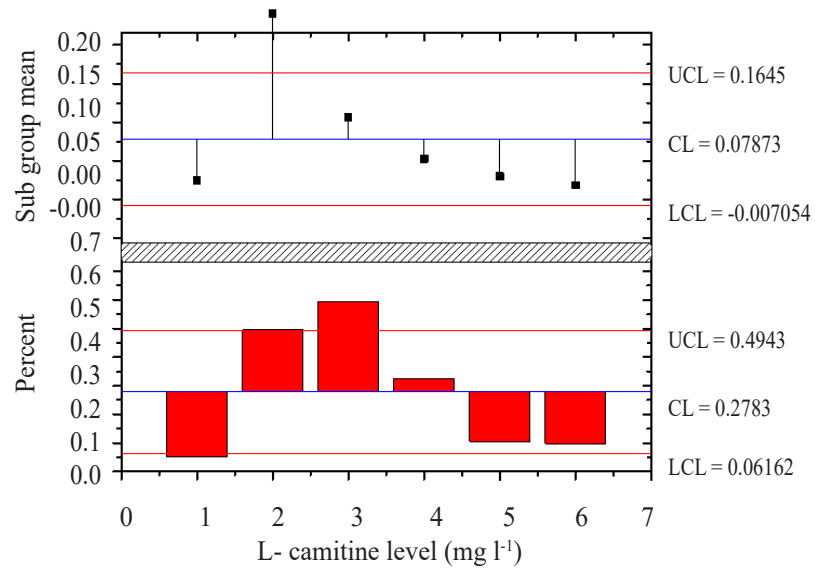

Fig. 4. Percentage variation in the size of rotifers in B. plicatilis enriched with different levels of L-carnitine after 5 days of batch culture $(1,2,3,4,5$ and 6 indicates $0,1,10,100$ and $1000 \mathrm{mg} \mathrm{l}^{-1}$ of L-carnitine respectively). p values are given on the top of bars $(\mathrm{p}<0.05)$

(Table 1). Fatty acid composition of rotifers enriched with $N$. salina, L. carnitine and S-presso are given in Table 1. The enrichment effects were found to be highly significant $(p<0.01)$. The high PUFA content in L-carnitine enriched rotifers was mainly due to the contribution of $18: 3 n-3$ to the total PUFA content. The total unsaturated n-3 fatty acids, HUFA, DHA, EPA, AA levels and their ratios showed differences among the three different enrichment diets (Table 3).

Initial mean wet weight of the newly hatched fish larvae was $0.75 \pm 0.2 \mathrm{mg}$. The larval growth was recorded after 15 days in different treatments. Larvae fed with L-carnitine enriched rotifer gained maximum weight $(65.67 \pm 1 \mathrm{mg})$ followed by larvae fed with $N$. salina enriched rotifer $(43.12 \pm 1 \mathrm{mg})$ and S-presso enriched rotifers $(42.2 \pm 0.04 \mathrm{mg}$ (Fig. 5)

Number of days taken for the first pigmentation i.e., from translucent colour to dull black colour was recorded in larvae fed with different enrichment diets. In L-carnitine and S-presso enriched feeding, first pigmentation appeared in 3 days, whereas it took 4 days in N. salina enriched rotifer (Table 4). Number of days taken to show initial signs of metamorphosis also varied with different feeds (Table 4). In L-carnitine, it took only 9 days, followed by 10 days in both $N$. salina and S-presso enriched rotifers.

Clown fish larval survival percentage indicated that L-carnitine enriched rotifers showed the highest survival of $70 \%$, followed by N. salina with $68 \%$ and S-presso $52 \%$. Larvae fed with L-carnitine enriched rotifers attained the highest weight gain of $56.92 \pm 0.2 \mathrm{mg}$, followed by S-presso with a weight gain of $48.74 \pm 1 \mathrm{mg}$. Larvae fed with $N$. salina enriched rotifers attained a maximum 
Table 1. Total lipids content and fatty acid (area percentage) of rotifers nutritionally enriched with $N$. salina, L. carnitine and S-presso

\begin{tabular}{|c|c|c|c|}
\hline Fatty acids & N. salina & L-carnitine & S-presso \\
\hline $8: 0$ & $0.495 \pm 0025$ & $0.69 \pm 0.06$ & $0.085 \pm 0015$ \\
\hline 10: 0 & 0 & 0 & 0 \\
\hline 12: 0 & $0.31 \pm 0.03$ & $0.455 \pm 0.025$ & $0.36 \pm 0.06$ \\
\hline 14: 0 & $6.45 \pm 0.35$ & $032 \pm 0.035$ & $4.54 \pm 0.16$ \\
\hline 16: 0 & $36.61 \pm 119$ & $4.615 \pm 0.495$ & $6.25 \pm 0.36$ \\
\hline $16: \ln 7$ & $17.19 \pm 0.99$ & $28.925 \pm 0.575$ & $32.185 \pm 0.625$ \\
\hline 18: 0 & $0.56 \pm 004$ & $16.005 \pm 0.805$ & $4.09 \pm 002$ \\
\hline 18: $\ln 9$ & $9.02 \pm 0.28$ & $28.96 \pm 0.08$ & $7.26 \pm 0.025$ \\
\hline $18: 2 n-6$ & $7.13 \pm 0.37$ & $8.62 \pm 0.295$ & $8.17 \pm 0.12$ \\
\hline $18: 3 n-3$ & $18.23 \pm 1.5$ & $21.03 \pm 0.22$ & $17.55 \pm 2.35$ \\
\hline 20: 0 & 0 & $7.62 \pm 0.13$ & $0.32 \pm 0.035$ \\
\hline 20: 1 & 0 & $0.49+0.04$ & 0 \\
\hline $20: 4 n-6$ & $0.405 \pm 0.025$ & $29.12 \pm 0.17$ & $13.925 \pm 0.725$ \\
\hline $20: 5 n-3$ & $16.685 \pm 0.385$ & $2.09 \pm 0.055$ & 0 \\
\hline $22: 6 n-3$ & $0.79 \pm 0.03$ & $29.12 \pm 0.170$ & 0 \\
\hline Unidentified & $4.08 \pm 0.26$ & $7.71 \pm 0.055$ & 0 \\
\hline$\Sigma$ saturated & $44.425 \pm 0.795$ & $46.215 \pm 1.295$ & $3282 \pm 0.665$ \\
\hline$\Sigma$ unsaturated & $51.22 \pm 078$ & $76.78 \pm 0.465$ & $53.1 \pm 0.065$ \\
\hline$\Sigma$ HUFA & $17.475 \pm 0.415$ & $33.2 \pm 0.1$ & $14.305 \pm 0.695$ \\
\hline$\Sigma \mathrm{n}-3$ fattyacids & $17.475 \pm 0.415$ & $54.23 \pm 0.12$ & $17.55 \pm 2.35$ \\
\hline$\Sigma \mathrm{n}-6$ fattyacids & $7.535 \pm 0.345$ & $10.71 \pm 0.35$ & $8.17 \pm 0.12$ \\
\hline$\Sigma$ MUFA & $2621 \pm 0.71$ & $11.84 \pm 0.005$ & $43.47 \pm 0.13$ \\
\hline$\Sigma$ PUFA & $7.535 \pm 0.345$ & $3174 \pm 0.57$ & $9.63 \pm 0.065$ \\
\hline$n-3 / n-6$ & $2.326576 \pm 0.161$ & $506349 \pm 0.165$ & $0.178703 \pm 0.026$ \\
\hline DHA/EPA & $0.047348 \pm 0.07792$ & $0.027289 \pm 0.041$ & $0.14011 \pm 1.588$ \\
\hline $\mathrm{EPA} / \mathrm{AA}$ & $41.19753 \pm 15.4$ & $11.60417 \pm 36.25$ & $13.933 \pm 3.090909$ \\
\hline
\end{tabular}

Values are means for two replicate samples \pm SE

DHA: EPA: AA ratios: $N$. salina fed rotifers $-0.4: 8.4: 0.2$, S-presso

enriched rotifers $-0.2: 7.0: 0.05$, L-carnitine enriched rotifers $1: 7: 0.5$.

growth rate of $39.41 \pm 3 \mathrm{mg}$. Observations during metamorphosis of the larvaeindicated thatfirstpigmentation in larvae fed with L-carnitine and S-presso enriched

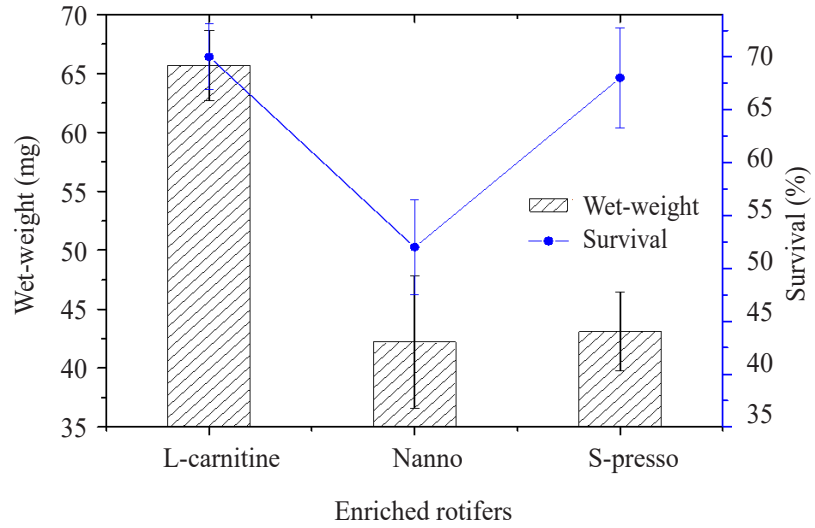

Fig. 5. Weight (mg) and survival (\%) of A. clarkii larvae fed with different diets

rotifers appeared in 3-4 days time while in $N$. salina group it took 4-5 days for first pigmentation. Larvae enriched with L-carnitine took 10 days for metamorphosis while S-presso and N.salina enriched groups took 11 and 12 days respectively (Table 4).

In the present investigation, it was found that L-carnitine enrichment led to better performance of rotifers in terms of increased population density In addition, L-carnitine enriched rotifers were found to perform better in larval rearing of $A$. clarkii. L-carnitine (1500 $\mathrm{mg} \mathrm{l}^{-1}$ ) enrichment through rotifer in the rearing system of European seabass has shown positive results (Santulli et al., 1990). In the present study, 38-50\% enhancement in population density of rotifer was observed in 1-100 $\mathrm{mg} \mathrm{l}^{-1} \mathrm{~L}$-carnitine supplemented treatments. Rotifers enrichment at $1000 \mathrm{mg} \mathrm{l}^{-1} \mathrm{~L}$-carnitine revealed $100 \%$ mortality on $10^{\text {th }}$ day, which may be attributed to the toxic effect of high concentration of L-carnitine.

Watanabe et al. (1983) observed that the nutritional quality of rotifers improved by feeding them on algae or, on emulsified pollock or squid oil prior to their transfer into fish tanks. The relationship between the $n-3$ and $n-6$ fatty

Table 3. DMRT grouping for total fatty acid fraction of rotifers enriched with various diets

\begin{tabular}{lllllll}
\hline Enrichments & $\Sigma$ Unsaturated & HUFA & PUFA & $\mathrm{n}-3$ & DHA/EPA & EPA/AA \\
\hline$N$. salina & $51.22^{\mathrm{b}}$ & $17.48^{\mathrm{b}}$ & $7.54^{\mathrm{c}}$ & $17.36^{\mathrm{b}}$ & $0.05^{\mathrm{b}}$ & $41.3^{\mathrm{b}}$ \\
L-carnitine & $76.31^{\mathrm{a}}$ & $33.31^{\mathrm{a}}$ & $31.76^{\mathrm{a}}$ & $54.11^{\mathrm{a}}$ & $0.15^{\mathrm{a}}$ & $25.23^{\mathrm{a}}$ \\
S-presso & $53.03^{\mathrm{b}}$ & $22.03^{\mathrm{b}}$ & $9.03^{\mathrm{c}}$ & $3.03^{\mathrm{c}}$ & $0.2^{\mathrm{a}}$ & $14.2^{\mathrm{c}}$ \\
\hline
\end{tabular}

Table 4. Pigmentation, metamorphosis stages (days), growth (mg) and survival (\%) of A. clarkii fed rotifers enriched with L-Carnitine, S-presso and $N$. salina for a period of 15 days

\begin{tabular}{lllll}
\hline Enrichment media & Wet weight gained $(\mathrm{mg})$ & Pigmentation $(\mathrm{DPH}) *$ & Metamorphosis $(\mathrm{DPH}) *$ & Survival rate $(\%)$ \\
\hline L-Carnitine & 65.6 & 3 & 9 & 70 \\
S-presso & 42.2 & 4 & 10 & 52 \\
N. salina & 43.12 & 3 & 10 & 68
\end{tabular}

*DPH: Days post-hatch 
acid series and more recently, the DHA/EPA, EPA/AA and DHA: EPA: AA ratios seem to be indicators of best survival and growth of marine fish larvae (Sargent et al., 1997). Table 1 shows that DHA, EPA and AA contents were high in L-carnitine enriched rotifers compared with other groups.

In this study, rotifer fed with $N$. salina gave optimum fatty acid profile especially HUFA and n-3 fatty acids, the n-3 / n-6, DHA / EPA and EPA / AA ratios. The total HUFA fraction in the enriched rotifers revealed that S-presso enriched rotifers contain a maximum percentage of HUFA fraction, in fact the major contribution is from the DHA and EPA fatty acids (Sargent et al., 1997). S-presso enriched rotifers have more $20: 4 n-6$ compared to $N$. Salina, but lesser than L-carnitine which has an essential function in producing eicosanoids. Arachidonic acid is essential for certain marine finfishes (Castell et al., 1994). In marine finfish larvae, the conversion of EPA to DHA is possible which can meet the requirement of DHA (Castell et al., 1994).

Clown fish larvae can be reared up to metamorphosis with enriched rotifers. Rotifers and brine shrimp nauplii are the two major potential live feed that are used for initial feeding in all types of marine fish larval hatcheries (AjithKumar and Balasubramanian, 2009; Dhaneesh et al., 2012). Healthy larvae in good water conditions usually metamorphose over a three-day period because of proper feed acceptability and fast swimming compared to weak larvae (Sargent et al., 1997). Rotifers enriched with S-presso and micro alga N. Salina contained EFA such as $20: 5 \mathrm{n}-3,22: 6 \mathrm{n}-3$ and PUFA like $20: 4 \mathrm{n}-6$. In the present investigation, significant difference was observed in the growth and survival of clown fish larvae fed with DHA enriched live food (high DHA/EPA ratio) i.e., S-presso, L-carnitine and N. salina enriched rotifers. However, pigmentation success was significantly better in clown fish larvae fed with L- carnitine. Recent research has shown that the n-6 HUFA, arachidonic acid (20:4n-6 or AA) was also important for growth, survival and stress resistance in flounder (Baker et al., 1998). DHA must be present in the diet to maximise the survival of larvae of damselfish, Acanthochromis polyacanthus (Southgate and Kavanagh, 1999). The AA was nutritionally more important in tropical species than in temperate species. $N$. salina contained relatively high levels (4.6\%) of AA (Thrush et al., 1993). In the present study, the rotifer enriched with L-carnitine and $N$. salina satisfied the AA requirement of clown fish larvae. Sargent et al. (1997) have detailed that both the quantity and proportions of DHA, EPA and AA were vital in marine fish larval nutrition and suggested that the optimum ratios may vary with species but would be in the range of 10:5:1 for DHA: EPA: AA.

Rotifers enriched with L-carnitine showed highly significant results in terms of growth and population density. The present results recommend that the optimal dose for
L-carnitine enrichment in rotifer culture medium is $1 \mathrm{mg} \mathrm{l}^{-1}$. Rotifers enriched with L-carnitine also enhanced clown fish larval growth. The present study also revealed that commercial L-carnitine and S-presso are good for long and short term rotifer enrichment respectively. $N$. salina enrichments is also advisable for rotifer enrichment in terms of total unsaturated fatty acids.

\section{Acknowledgements}

Authors are grateful to the authorities of Annamalai University for providing facilities and the Centre for Marine Living Resources and Ecology, Ministry of Earth Sciences, Govt. of India for financial support.

\section{References}

Ajith Kumar, T. T. and Balasubramanian, T. 2009. Broodstock development, spawning and larval rearing of the false clownfish, Amphiprion clarkii in captivity using estuarine water. Curr. Sci., 97: 1483-1486.

Albentosa, M., Perez-Camacho, A., Labarta, U. and FernandezReiriz, M. J. 1997. Evaluation of freeze-dried microalgal diets for the seed culture of Ruditapes decussatus using physiological and biochemical parameters. Aquaculture, 154: 305-321.

Baker, S., Alves, D. and Bengston, D. A. 1998. Effects of fatty acid enriched rotifers and Artemia on survival, growth and population of summer flounder Paralichthys dentratus larvae. J. World Aquac. Soc., 29: 224-227.

Bligh, E. G. and Dyer, W. J. 1959. A rapid method of total lipid extraction and purification. Can. J. Biochem. Physiol., 37: 911-917.

Cahu, C. L., ZamboninoInfante, J. L., Peres, A., Quazuguel, P. and Le Gall, M. M. 1998. Algal addition in seabass Dicentrarchus labrax larvae rearing: effect on digestive enzymes. Aquaculture, 161: 479-489.

Castell, J. D., Bell, J. G., Tocher, D. R. and Sargent, J. R. 1994. Effects of purified diets containing different combinations of arachidonic and docosahexaenoic acid on survival, growth and fatty acid composition of juvenile turbot Scophthalmus maximus. Aquaculture, 128: 315-333.

Dhaneesh, K. V., Ajith Kumar, T. T., Swagat, G. and Balasubramanian, T. 2012. Breeding and mass scale rearing of clownfish Amphiprion percula: Feeding and rearing in brackishwater. Chinese J. Oceanol. Limnol., 30: 528-534.

Dhert, P., Rombaut, G., Suantika, G. and Sorgeloos, P. 2001. Advancement of rotifer culture and manipulation techniques in Europe. Aquaculture, 200: 129-146.

Duncan, A. 1989. Food limitation and body size in life cycle of planktonic rotifers and cladocerans. Hydrobiologia, 186/187: 11-28.

Emaus, R. K. and Bieber, L. L. 1983. A biosynthetic role of carnitine in the yeast Torulopsis bovina. J. Biol. Chem., 258: 13160-13165. 
Fu, Y., Hirayama, K. and Natsukari, Y. 1991. Morphological differences between two types of the rotifer Brachionus plicatilis O. F. Muller. J. Exp. Mar. Biol. Ecol., 151: 29-41.

Hagiwara, A., Gallardo, W. G., Assavaaree, M., Kotani, T. and Araujo, A. B. 2001. Live food production in Japan: recent progress and future aspects. Aquaculture, 200: 111-127.

Olsen, Y., Reitan, K. I. and Vadstein, O. 1993. Dependence of temperature on loss rates of rotifers lipids and $\Sigma_{3}$ fatty acids in starved Brachionus plicatilis cultures. Hydrobiologia, 255/256: 134-155.

Rico-Martınez, R. and Dodson, S. I. 1992. Culture of rotifers Brachionus sp. Pallas. Aquaculture, 105: 191-199.

Santulli, A., Puccia, E. and D'Amelio, V. 1990. Preliminary study on the effect of short-term carnitine treatment on nucleic acids and protein metabolism in sea bass (Dicentrarchus labrax L.) fry. Aquaculture, 87: 85-89.

Sargent, J. R., McEvoy, L. A. and Bell, J. G. 1997. Requirements, presentation and sources of polyunsaturated fatty acids in marine fish larval feeds. Aquaculture, 155: 85-101.

Segner, H., Orejana-Acosta, B. and Juario, J. V. 1984. The effect of Brachionus plicatilis grown on three different species of phytoplankton on the ultra-structure of the hepatocytes of Chanos chanos (Forskal) fry. Aquaculture, 42: 109-115.
Southgate, P. C. and Kavanagh, K. 1999. The effect of dietary $n-3$ highly unsaturated fatty acids on growth, survival and biochemical composition of coral reef demersal fish, Acanthochromis polycanthus. Aquat. Living Resour., 12: 31-36.

Thrush, M., Navas, J. M., Ramos, J., Bromage, N. R., Carrillo, M. and Zanuy, S. 1993. The effect of artificial diets on lipid and total fatty acid composition of cultured seabass (Dicentrarchus labrax) eggs. Actas IV Congreso. Nacional de Acuiculture, 37-42.

Watanabe, T., Kitajima, C. and Fujita, S. 1983. Nutritional value of live organisms used in Japan for mass propagation of fish: a review. Aquaculture, 34: 115-143.

Yoshimatsu, T., Imoto, H., Hayashi, M., Toda, K. and Yoshimura, K. 1997. Preliminary results in improving essential fatty acids enrichment of rotifer culture in high density. Hydrobiologia, 358: 153-157.

Zar, J. H. 1999. Biostatistical analysis. Prentice-Hall, Illinois, USA. p. 1-662.

Zhang, D. M., Huang, Q., Zhou, J. X. and Wu, L. F. 2002. Effects of L-carnitine on growth performance and muscle composition of Cyprinus carpio (L.) fed diets with different levels of protein. J. Jilin Agric. Univ., 24: 82- 87. 